\title{
Active and passive immunization in the extremely preterm infant
}

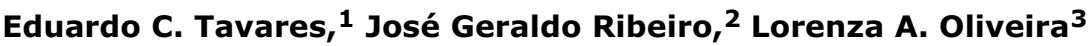

\begin{abstract}
Objective: A review of the indications, contraindications, ideal timing, immunogenic efficacy and reactogenicity (adverse events) of active and passive immunization for extremely preterm infants.

Sources of data: Research in classic textbooks on pediatric infectology and in the electronic databases MEDLINE, Lilacs, PubMed and Akwanmed, using the following health sciences descriptors: premature, very low weight newborn, immunization, active immunization, passive immunization, vaccines, immunoglobulin.

Summary of the findings: The immunization of extremely premature very low birth weight infants is a huge challenge for pediatricians because there is insufficient knowledge about the efficacy of immune responses and undesirable reactions. Possibly for this reason, it is common that such children are found to be behind schedule with their immunizations or to have been incompletely immunized. Notwithstanding the scarcity of publications on the theme, in principal young gestational age and low birth weight should not be considered limiting factors to clinically stable premature newborns being immunized at the same chronological age indicated for full term children.

Conclusion: Based on the available evidence it not possible to propose vaccine and immunoglobulin administration practice for extremely premature or very low weight newborn babies that is definitive. With rare exceptions however, such as the BCG vaccine, the tendency is to maintain the same active immunization program as for babies born full term, irrespective of weight or gestational age at birth. Passive immunization merits special attention, having more liberal indications in this group of newborn babies.
\end{abstract}

J Pediatr (Rio J). 2005;81(1 Suppl):S89-S94: Premature, very low birth weight infants, immunization, active immunization, passive immunization, vaccines, immunoglobulin.

\section{Introduction}

The acquisition of new technologies for the care of premature newborns has allowed an increase in the survival rates of newborn babies (NBs) with extremely low gestational ages and birth weights. The way that these children behave immunologically in the face of an antigenic provocation is not yet known, with more elaborate studies being necessary to investigate many different features of their immune responses. ${ }^{1-4}$ This lack of

1. PhD. Adjunct professor, Department of Pediatrics, School of Medicine, Universidade Federal de Minas Gerais (UFMG), Belo Horizonte, MG, Brazil.

2. MSc., Assistant professor, Faculdade de Ciências Médicas de Minas Gerais (FCMMG). Physician. Coordinator of the Immunization Department of Secretaria de Estado da Saúde, Belo Horizonte, MG, Brazil.

3. Neonatologist, Neonatal Unit, Hospital das Clínicas, UFMG. Former assistant professor, Department of Pediatrics, School of Medicine, Universidade Federal de Minas Gerais (UFMG), Belo Horizonte, MG, Brazil.

Suggested citation: Tavares EC, Ribeiro JG, Oliveira LA. Active and passive immunization in the extremely preterm infant. J Pediatr (Rio J). 2005;81(1 Suppl):S89-S94. knowledge may be related to the results of a study which found significant delays in scheduled immunizations among premature infants when compared with NBs born to full term in the same region, at 12 months of age, (odds ratio $(O R)=0.556 ; p=0.001), 24$ months $(O R=0.439$; $\mathrm{p}<0.001)$, and 36 months $(O R=0.446 ; \mathrm{p}<0.001) .{ }^{1}$ In a different study, performed in Switzerland, ${ }^{5}$ the authors concluded that the principle reasons for delay in the schedule include insufficient information for the parents and prolonged hospital stays. They recommended special attention to the immunization of preterms, with emphasis on the administration of vaccines at the correct chronological age and detailed guidance for parents at the point of hospital discharge.

There appears to be consensus that, with the exception of special cases, NBs with birth weights above $2 \mathrm{~kg}$ or gestational ages over 35 weeks should be vaccinated at the same ages as those born to full term since no differences have been found between these two groups. 6-9 The challenge is in finding the ideal immunization schedule for extremely premature infants, taking into account the 
natural limitations of their immune systems both with respect of their cellular and humoral responses. A number of different aspects of these patients' immune response capacity still need to be clarified. The most important are the issues of the efficacy and reactogenicity of the various vaccines. Studies of the different subsets that make up premature infants are rare and the few that exist were, in general, performed with small numbers of participants. It is to be expected that the response to vaccines is not the same for these groups. In addition to their gestational age and weight, the peculiarities of this group of patients include the medical interventions they undergo during the neonatal period, the frequent use of medication, especially corticosteroids, the administration of blood products and immunoglobulins and the prolonged length of hospital stay, which itself often passes the dates envisaged for the start of the vaccination schedule.

In principal, young gestational age and low birth weight are not limiting factors for clinically stable premature NBs to be immunized. ${ }^{6}$ A French study ${ }^{10}$ of vaccination efficacy and tolerance among premature children corroborates this idea, stating that immunological maturity is more dependent on chronological age than on gestational age. With the exception of the BCG vaccine, they also claim that neither the duration of immunity nor the safety of the vaccines are modified by prematurity. Other studies, however, ${ }^{11,12}$ have shown a reduced immunoresponse to certain vaccines when administered to extreme preterms $(<1,000 \mathrm{~g}$ and $<29$ weeks' gestational age), although the levels of antibodies produced continue to be sufficient to induce immunity and prevent disease. ${ }^{13-15}$ Recent work has demonstrated that the clinical stability of children, generally assessed as the observation of a steady weight gain pattern, has a better predictive value for immunoresponse than does birth weight in isolation. ${ }^{16,17}$ The doses used for preterm and low weight NB immunization should be the same as for fullterm NB and should not be fractioned. However, certain precautions should be taken to minimize muscle damage. The needle used for intramuscular injections should be suitable for the low muscle mass of preterm NBs and be, therefore, smaller than that used for fullterm NBs. ${ }^{6}$

With respect of the incidence of adverse effects related to vaccination of preterm and low weight NBs, the relative immaturity of their immune systems could reduce the reactogenicity of several vaccines, resulting in reduced incidence of undesirable reactions. However, reports exist of apnea up to 72 hours after administration of the triple bacterial vaccine against diphtheria, tetanus and pertussis (DTP) (whole cell) to NBs < 31 weeks' gestational age, which was not observed after the use of the acellular vaccine. ${ }^{18-20}$ Benign febrile convulsive crises were also reported more frequently with preterms than with infants born to full term after being given the heptavalent pneumococcal vaccine concurrently with DTP (whole cells) and the vaccine against type $b$ hemophilus. ${ }^{6}$

While the study of the immunogenicity and adverse reactions of this subset of patients is still far from completed, the present article has the objective of a review of what is already known about active and passive immunization of extremely preterm and very low birth weight NBs, reaffirming the relative scarcity of work in the literature, primarily due to the recent nature of these patients' survival and the short follow-up period of those who have already been immunized.

\section{Passive immunization}

Passive immunization can be defined as the administration of antibodies to a receptor, with the objective of providing immediate protection against a microbial agent, a toxic substance or cell. It is generally indicated when a nonimmune individual is exposed to an infectious disease and active immunization is not available (for example, respiratory syncytial virus - RSV) or is contraindicated (for example, varicella for immunodepressed patients) or had not been given before exposure (for example, rabies or tetanus).

The general indications for passive immunization can be summed up as (1) congenital or acquired immunodeficiencies; (2) susceptible individuals exposed to specific diseases, in particular if considered at high risk for complications (immunodepressed) or when there is not time for adequate protection to be afforded via active immunization in isolation (measles, rabies or hepatitis B); (3) certain diseases when the antibody administered can overcome a toxin (botulism, diphtheria, tetanus) or inflammatory response (Kawasaki disease).

A number of different types of products are currently used for passive immunization:

- standard immunoglobulin, available in intramuscular and intravenous forms (IVIG);

- hyperimmune immunoglobulin (specifics);

- animal serum and antitoxins;

- antibodies monoclonal.

Passive immunization is not always effective and duration is variable ( 1 to 6 weeks). There are side effects with all forms of administration and precautions should be taken, in particular when using products of animal origin.

Premature NBs, in particular those considered extremely premature, invariably exhibit low levels of maternal IgG, reaching levels of just $100 \mathrm{mg} / \mathrm{dl}$ during the first months of life. ${ }^{21}$ These levels may be even lower depending on the presence of the intercurrent clinical conditions that they often present, such as lung disease (with accumulation of liquid in the lungs), stress (with increased IgG catabolism) and multiple blood samples. Prolonged hospital stays and the invasive procedures that they undergo, allied to the immaturity of their phagocytosis, complement and T-cell systems, deficiencies of IgM and IgA and an immunoresponse that is not very agile, characterize extremely premature infants as a class of patients that is extraordinarily susceptible to infection.

There have been many attempts over the years to improve the immune status of these premature infants and reduce the number of infections. During the sixties, studies of the administration of immunoglobulins did not result in significant differences in their survival. ${ }^{22,23}$ During the last decade, with the advent of intravenous immunoglobulin and 
the increase in the survival rates of extremely premature infants, there was a renewed interest in the passive immunization of these children, with controversial results. Thus, a National Institutes of Health (NIH) consensus document published in 1990,24 recommended that intravenous immunoglobulin should not be routinely employed for the prophylaxis of infections in premature and low weight children, although it could be of value in selected premature subsets. Recently, in 2001, in a Cochrane Library meta-analysis of 15 studies, a reduction of $3-4 \%$ was demonstrated in the rate of infections among treated preterms, with no difference in mortality 25 .

Specific monoclonal antibodies have been known for many decades, but have only been used recently therapeutic ends. One of these antibodies, palivizumab, against RSV, is one of the newest weapons for passive immunization of extremely premature newborns, particularly those considered at risk of getting the infection during their first years of life.

Indications for passive immunization of premature and low weight NBs will be dealt with below, including prophylactic and therapeutic use, covering the available options for a number of different related agents.

\section{Passive immunization for bacterial infections}

Intravenous immunoglobulin is not recommended for routine infection prevention in the extremely premature infant. Nevertheless, it can be used, in selected cases, as an adjuvant therapy, particularly for premature infants with neutropenia. 26,27

\section{Passive immunization for viral infections}

Hepatitis $A$

If the mother presents a diagnosis of the acute disease between 2 weeks before and 1 week after birth, standard immunoglobulin should be administered to the NB in a single $0.5 \mathrm{ml}$ intramuscular (IM) dose. 28

\section{Hepatitis $B$}

Passive immunization, i.e. the administration of hyperimmune immunoglobulin against hepatitis B (IGHB) at a dose of $0.5 \mathrm{ml} \mathrm{IM}$, is indicated for all premature or low weight NB whose mothers are HbsAg positive, by 12 hours postpartum. If the immunological status of the mother is unknown and the premature infant had birth weight $\geq 2,000 \mathrm{~g}$, then the mother's serology should be taken soon after birth and, if positive, the immunoglobulin should be administrated to the NB by the seventh day of life. Premature infants with birth weights of less than $2,000 \mathrm{~g}$ whose mother's serology is unknown should receive immunoglobulin by 12 hours of life, unless maternal serology becomes available and is negative. It is important to point out that the Health Ministry of Brazil has not yet made this recommendation and Centers of Special Immunobiological Excellence (CRIES - Centros de Referência de Imunobiológico Especial) are not authorized to release IGHB for the children of mothers with unknown serology. Hyperimmune immunoglobulin is not indicated for premature infants whose mothers are seronegative for HBsAg. 29,30

\section{Varicella}

Passive immunization with IM human immunoglobulin anti-varicella-zoster (HIGAVZ), at a dose of $125 \mathrm{U}$ $(1.25 \mathrm{ml})$, should be performed for selected groups of NBs and to exposed premature NBs, considered at risk of severe infection grave: (1) NBs whose mothers have had varicella 5 days before or 2 days after birth, (2) hospitalized preterms, with a history of exposure and gestational ages $\geq 28$ weeks and mothers susceptible to varicella, (3) hospitalized preterms with history of exposure gestational ages $\leq 28$ weeks or birth weights $\leq 1,000 \mathrm{~g}$, irrespective of the immunological status of the mother. ${ }^{31}$

\section{RSV}

Acute infection of the respiratory tract by RSV (bronchiolitis or pneumonia) is the most common cause of the hospital admission of NBs and young infants and, although the majority of these have a case with a benign outcome, some may present severe or even fatal disease. Prematurity, congenital heart disease, chronic lung disease and immunodeficiency are the risk factors that most worsen the prognosis of these children and the use of passive immunization is indicated in these cases to prevent or modify the course of infection 30,32 . Two products are available for prevention of RSV infections: intravenous anti-RSV immunoglobulin RSV (RSV-IGIV), licensed in 1996 and palivizumab, a humanized monoclonal antibody directed at the F glucoprotein of RSV for intramuscular use, licensed since 1998.

The administration of venous immunoglobulin to preterms and high risk children has reduced the number of RSV infections and, therefore the length of hospital stay in the neonatal unit, 33 in addition to offering the additional benefit of reducing the number of respiratory infections by other pathogens (influenza) and otitis media in the patients treated. ${ }^{34}$ RSV-IGIV is given intravenously at a dose of $15 \mathrm{ml} / \mathrm{kg}$, in a 4-hour infusion, monthly, for 5 months in the year. In contrast with palivizumab, the immunoglobulin should not be used on children with cyanotic congenital heart disease because of the high incidence of side effects. ${ }^{35}$ Children who have received RSV-IGIV should only be immunized against measles and varicella 9 months after the last dose. 32,35

Palivizumab neutralizes types A and B of RSV and is 50100 times more potent than RSV-IGIV. ${ }^{36}$ Its use on premature infants and children under 2 years old with chronic lung disease resulted in a reduction in hospital admissions for RSV and days on oxygen therapy. However, its use does not affect rates of hospital admission for other pathogens or the incidence of otitis media among those who are vaccinated. 35 It is used intramuscularly at a dose of $15 \mathrm{mg} / \mathrm{kg}$, monthly, for the 5 months of the year with high incidence of infections by RSV. ${ }^{37}$ Candidates for prophylaxis are: $30,32,35$ 
- children less than 2 years of age, suffering from chronic lung disease, who need to be treated 6 months before the season with high RSV incidence. Both RSV-IGIV and palivizumab can be used, but palivizumab is more indicated because of ease of administration, safety and efficacy. Children with severe lung disease may need two courses of treatment over 2 consecutive years;

- premature NBs with gestational ages $\leq 32$ weeks, with or without chronic lung disease: premature NBs $\leq 28$ weeks should receive prophylaxis for 12 months and those born at 29 to 32 weeks, for the first 6 months of life.

- premature infants with gestational ages from 32 to 35 weeks, less than 6 months old, who have two or more of the following risk factors: severe neuromuscular diseases, passive exposure to smoking or other pollutants, school age siblings, collective childcare or congenital airway anomalies.

- infants aged 2 years or less, with hemodynamically significant, cyanotic or acyanotic heart disease should receive palivizumab monthly during the months of high incidence of RSV infection. Children considered high risk and their contacts should receive the influenza vaccine from 6 months of age onwards.

Neither RSV-IGIV nor palivizumab should be used to treat infections by RSV. They are not recommended for prophylaxis against hospital acquired infections. For highrisk hospitalized newborns, the best way of preventing infection by RSV is strict observance of infection control standards. 35

\section{Active immunization}

There are many doubts over the best active immunization schedule for small preterms. As has been said earlier, prolonged periods of hospital admission and the use of medication or blood products can interfere in vaccine indications.

The use of corticosteroids, whether by via parenteral or oral, on consecutive or alternative days for more than 14 days, at doses equivalent to or greater than $2 \mathrm{mg} / \mathrm{kg} /$ day of prednisone contra-indicates vaccination with live viruses, but not other vaccines. Notwithstanding even live virus vaccines can be administered after 1 month's suspension of corticosteroids. 6,9,38

Blood products can interfere with the efficacy of live virus vaccines, which should be given some time after their use, or even repeated if the epidemiological situation does not allow them to be delayed. In the case of immunoglobulins this period is generally taken to be 3 months, with the exception of 5 months for immunoglobulin against varicellazoster. After transfusion with erythrocytes or whole blood, an interval of 5 or 6 months respectively should be observed.

It is believed that monoclonal antibodies do not interfere with vaccinations. $6,9,38$ It is not uncommon for premature infants to have hospital stays of more than 2 or 3 months and those children who are in stable clinical conditions should receive the appropriate vaccinations for their chronological ages. Notwithstanding, NBs with birth weights of less than $2,000 \mathrm{~g}$ may require a modified vaccination schedule with respect of hepatitis $B$, depending on the immunological status of the mother at the time of birth. 6,7

Before discharge, members of the NBs household should be vaccinated against influenza. The NBs themselves should also be vaccinated from 6 months of age. ${ }^{2,6,9}$ All health professionals whop deal with these children must be immunized against measles, rubella, mumps, whooping cough, varicella, hepatitis A and Influenza. This last should be repeated annually. 2,6,39

The principal vaccinations indicated for preterm NBs are discussed below:

- BCG: the BCG ID vaccine should not be given to children with weights of less than $2 \mathrm{~kg}$. This recommendation by the Brazilian Health Ministry's National Immunizations Program (PNI - Programa Nacional de Imunizações) is in accordance with international standards and must be adhered to. ${ }^{9}$ Nevertheless, no studies supporting this conduct were found in the literature researched.

- Hepatitis B: some studies have demonstrated a reduced proportion of children with levels of antibodies that are considered protective when the first dose of vaccine against hepatitis $B(\mathrm{HepB})$ is given at birth and with weight below $2 \mathrm{~kg} .^{7,11,40-42}$ Children with birth weights above $2 \mathrm{~kg}$ respond in a similar manner to those born to full term with appropriate weight. ${ }^{7,43}$ Vaccination from 1 month of age onwards presents an adequate response irrespective of birth weight, which authorizes vaccination at 2 months of age and any weight and from 1 month of age for clinically stable premature children at hospital discharge. $6,7,43$ Those NBs that received their first dose during the first month of life while weighing less than 2 $\mathrm{kg}$ should be given a fourth dose around 6 months after the third which makes the schedule as immunogenic as three doses for children whose weight was above 2 kg. 6,7,43 Those NBs whose mothers were HBsAg positive or whose serology was ignored should receive their first of vaccine during the first 12 hours of life, irrespective of weight, and be vaccinated with the four-dose schedule. Those with positive mothers should also receive hyperimmune immunoglobulin. ${ }^{38}$ No increase in the occurrence of adverse events among low weight NBs has been reported. 7,43

- DTP Vaccine: the greater frequency of adverse events with DTP vaccine is controversial, in particular the triple bacterial version with whole cells. Some studies report an increased occurrence of apnea, bradycardia and febrile convulsions among low birth weight NBs or those born at les than 31 weeks. 6,44 The use of acellular vaccines (DTaP) is more prudent whenever possible. Under no circumstances should vaccination be delayed, starting at 2 months of age, because of the occurrence of more severe whooping cough in these children. 6,7 The efficacy of the triple vaccines, acellular or not, has been demonstrated adequate for low weight children.

- $\quad H$. influenzae $(\mathrm{HiB})$ : immunization with the conjugated vaccine against $H$. influenzae group $B(\mathrm{HiB})$ from 2 
months of age allows low weight NBs to produce protective antibody levels by the end of the schedule, although these levels are reduced in very low weight infants. ${ }^{45,46}$

- Attenuated oral poliomyelitis (OPV) and inactivated injectable (IPV): there is not contraindication for the use of vaccines against poliomyelitis (attenuated or inactivated) from 2 months of life on for low weight NBs. However, while protective, antibody numbers may be lower, particularly for type 3 poliovirus, among very low weight NBs. ${ }^{7,15}$

- Pneumococcus: the ideal would be for all NBs to be vaccinated with the conjugated vaccine against pneumococcus, but if this is not possible, at least those with lung disease should be vaccinated. The vaccine can be given from 2 months of age onwards irrespective of weight. The protection conferred and also the occurrence of adverse events, appear similar for fullterm and preterm subsets. When applied concomitantly with the whole cell DTP vaccine, there is a discrete increase in the risk of convulsions among premature children. Similar findings were observed with the conjugated vaccine against meningococcus $C .{ }^{2,47}$

- Others: the triple viral vaccine against yellow fever and varicella should be given at the same ages as to fullterm children. 4,9

- Combined vaccines: with the appearance of new vaccines over recent years, the use of combined vaccines has become important. One combined vaccine, DTaP-HiB, was used in the United Kingdom at 2, 3 and 4 months with NBs of less than 32 weeks' gestation, resulting in reduced HIB efficacy. ${ }^{19}$ Notwithstanding, other studies showed an adequate response to the DTaP-HepB combination and even to a hexavalent DTaP-IPV-HepB$\mathrm{HiB}$ vaccine. The use of these combined vaccines will make the concomitant application of newer vaccines. ${ }^{48-50}$

$A$ recent study to assess the safety of the conjugated DTaP-IPV-HIB vaccine with 78 very low weight NBs, with mean weight of $1,045 \pm 357 \mathrm{~g}$ and gestational age of $28 \pm 2$ weeks, showed an incidence of $47 \%$ of cardiorespiratory events (apnea in 15\%; bradycardia in $21 \%$ and low saturation in $42 \%$ ). The majority of these events were benign and resolved themselves spontaneously or after mild stimulation. The authors concluded that these events did not represent a harmful impact on clinical course and that immunization was justified, even for the majority of vulnerable preterms. ${ }^{51}$

\section{References}

1. Langkamp DL, Hoshaw-Woodard S, Boye ME, Lemeshow S. Delays in receipt of immunizations in low-birth-weight children: a nationally representative sample. Arch Pediatr Adolesc Med. 2001; 155:167-72.

2. Siegrist C-A. Protection against infectious diseases early in life. Vaccinology: abstract book. Costa do Sauípe; 2003. p. 4-5.

3. McKechnie L, Finlay F. Update and timing of immunizations in preterm and term infants. Prof Care Mother Child. 1999;9:19-21.

4. Moyes C. Immunization of preterm babies. N Z Med J. 1999;112: 263-4.
5. Tillmann BU, Tillmann HC, Nars PW, Weber P. Vaccination rate and age of premature infants weighing < $1500 \mathrm{~g}$ : a pilot study in north-western Switzerland. Acta Paediatr. 2002;91:724-5.

6. American Academy of Pediatrics. Committee on Infectious Diseases. Active and Passive Immunization. In: Pickering LK, editor. Red Book: 2003 Report of the Committee on Infectious Diseases. 26th ed. Elk Grove Village, IL: American Academy of Pediatrics; 2003. p. 1-98.

7. Saari TN, American Academy of Pediatrics, Committee on Infectious Diseases. Immunization of Preterm and Low Birth Weight Infants. Pediatrics. 2003;112:193-8.

8. Succi RC. Vacinações em situações especiais. In: Sociedade Brasileira de Pediatria - Linha vacinas. Rio de Janeiro: Sociedade Brasileira de Pediatria; 2003.

9. Ministério da Saúde. Fundação Nacional de Saúde. Manual de Normas de Vacinação. $3^{a}$ ed. Brasília: Ministério da Saúde; 2002. p. 25-6.

10. Saliou P, Ajjan N, Guerin N. Efficacy and tolerance of vaccinations in premature infants. Arch Pediatr. 2002;9:629-37.

11. Lau YL, Tam A, Ng K, Tsoi N, Lam B, Lam P, et al. Clinical and laboratory observations - response of preterm infants to hepatitis B vaccine. J Pediatr. 1992;12:962-5.

12. American Academy of Pediatrics, Committee on Infectious Diseases. Update on timing of hepatitis $B$ vaccination for premature infants and for children with lapsed immunization. Pediatrics. 1994;94:403-4.

13. Belloni C, Chirico G, Pistorio A, Orsolini P, Tinelli C, Rondini G. Immunogenicity of hepatitis $B$ vaccine in term and preterm infants. Acta Pediatr. 1998;87:336-8.

14. Kirmani KI, Lofthus G, Pichichero ME, Voloshen T, D'Angio CT. Seven-year follow-up of vaccine response in extremely premature infants. Pediatrics. 2002;18:824-5.

15. Khalak R, Pichichero ME, D'Angio CT. Three-year follow-up of vaccine response in extremely preterm infants. Pediatrics. 1998; 101:597-603.

16. Patel DM, Butler J, Feldman S, Graves GR, Rhodes PG. Immunogenicity of hepatitis $B$ vaccine in healthy very low birth weight infants. J Pediatr. 1997;131:641-3.

17. Losonsky GA, Wasserman SS, Stephens I, Mahoney F, Armstrong $P$, Gumpper $K$, et al. Hepatitis B vaccination of premature infants: a reassessment of current recommendations for delayed immunization. Pediatrics. 1999;103:e14.

18. Ramsay ME, Miller E, Ashworth LA, Coleman TJ, Rush M, Waight PA. Adverse events and antibody response to accelerated immunization in term and preterm infants. Arch Dis Child. $1995 ; 72: 230-2$.

19. Slack MH, Schapira D, Thwaites RJ, Burrage M, Southern J, Andrews $\mathrm{N}$, et al. Immune response of premature infants to meningococcal serogroup $\mathrm{C}$ and combined diphtheria-tetanus toxoids-acellular pertussis-haemophillus influenza type $B$ conjugate vaccines. J Infect Dis. 2001;184:1617-20.

20. Schloesser RL, Fischer D, Otto W, Rettwitz-Volk W, Herden P, Zielen S. Safety and immunogenicity of an acellular pertussis vaccine in premature infants. Pediatrics. 1999;103:e60.

21. Ballow M, Cates KL, Rowe JC, Goetz C, Desbonnet C. Development of the immune system in very low birth weight (less than $1500 \mathrm{~g}$ ) premature infants: concentrations of plasma immunoglobulins and patterns of infections. Pediatr Res. 1986;20:899-904.

22. Diamond EF, Purugganan HB, Choi HJ. Effect of prophylactic administration on infection morbidity in premature infants. IMJ Ill Med J. 1966;130:668-70.

23. Steen JA. Gamma globulin in preventing infections in prematures. Arch Pediatr. 1960;77:291-4.

24. NIH Consensus Development Conference: Diseases, doses, recommendations for intravenous immunoglobulin. HLB Newsletter. 1990;6:73-8.

25. Ohlsson A, Lacy JB. Intravenous immunoglobulin for preventing infection in preterm and/or low birth weight infants. Cochrane Database Syst Rev. 2004;(1):CD001239.

26. Baker $\mathrm{CJ}$, Melish ME, Hall RT. Intravenous immunoglobulin for the prevention of nosocomial infection in low birth weight neonates. New Engl J Med. 1992;327:213-9.

27. Jenson $\mathrm{HB}$, Pollock $\mathrm{BH}$. The role of intravenous immunoglobulin for the prevention and treatment of neonatal sepsis. Semin Perinatol. 1998;22:50-63.

28. Crumpacker CS. Hepatitis. In: Remington JS, Klein JO. Infectious Diseases of the Fetus and Newborn Infant. 5th ed. Philadelphia: Saunders; 2001. p. 913-41. 
29. American Academy of Pediatrics, Committee on Infectious Diseases. Hepatitis B. In: Pickering LK, ed. Red Book: 2003 Report of the Committee on Infectious Diseases. 26th ed. Elk Grove Village, IL: American Academy of Pediatrics; 2003. p. 419-29.

30. Stiehm ER, Keller MA. Passive immunization. In: Feigin RD, Cherry JD, Demmler GJ, Kaplan SL. Textbook of Pediatric Infectious Diseases. 5th ed. Philadelphia: Saunders; 2004. p. 3182-220.

31. American Academy of Pediatrics, Committee on Infectious Diseases. Varicella-zoster Infections. In: Pickering LK, editor. Reed Book: 2003 Report of the Committee on Infectious Diseases. 26th ed. Elk Grove Village, IL: American Academy of Pediatrics; 2003. p. 672-86.

32. American Academy of Pediatrics, Committee on Infectious Diseases. Respiratory Syncycial Virus. In: Pickering LK, editor. Reed Book: 2003 Report of the Committee on Infectious Diseases. 26th ed. Elk Grove Village, IL: American Academy of Pediatrics; 2003. p. 523-8.

33. Groothuis JR, Simões EA, Hemming VG. Respiratory Syncycial Virus (RSV) infection in preterm infants and the protective effects of RSV immune globulin (RSVIG). Respiratory Syncycial Virus Immune Globulin Study Group. Pediatrics. 1995;95:463-7.

34. The Prevent Study Group. Reduction of respiratory syncycial virus hospitalization among prematures infants and infants with bronchopulmonary dysplasia using respiratory syncycial virus immunoglobulin prophylaxis. Pediatrics. 1997;99:93-9.

35. American Academy of Pediatrics, Committee on Infectious Diseases and Committee on Fetus and Newborn. Policy Statement. Revised Indications for the Use of Palivizumab and Respiratory Syncycial Virus Immune Globulin Intravenous for the Prevention of Respiratory Syncycial Virus Infection. Pediatrics. 2003; 112:1442-6.

36. Sanchez PB. Immunoprophylaxis of respiratory syncycial virus disease. Pediatr Infect Dis J. 2000;19:791-801.

37. The Impact - RSV Study Group. Palivizumab, a humanized respiratory syncycial virus monoclonal antibody, reduces hospitalization from respiratory syncycial virus infection in high risk infants. Pediatrics. 1998;102:531-7.

38. Ministério da Saúde. Fundação Nacional de Saúde. Manual dos Centros de Referência de Imunobiológicos Especiais. Brasília: Ministério da Saúde; 2002.

39. Rosenblum LS. Hepatitis A outbreak in a neonatal intensive care unit: risk factors for transmission and evidence of prolonged viral excretion among preterm infants. J Inf Dis. 1991;164: 476-82.

40. Linder N, Handsher R, German B, Sirota L, Bachman M, Zinger $S$, et al. Controlled trial of immune response of preterm infants to recombinant hepatitis $B$ and inactivated poliovirus vaccines administered simultaneously shortly after birth. Arch Dis Child Fetal Neonatal Ed. 2000;83:F24-7.

41. Freitas da Motta MS, Mussi-Pinhata MM, Jorge SM, Tachibana Yoshida CF, Sandoval de Souza CB. Immunogenicity of hepatitis $B$ vaccine in preterm and full term infants vaccinated within the first week of life. Vaccine. 2002;20:1557-62.
42. Charareewong $S$, Jirapongsa $A$, Lokaphadhana K. Immune response to hepatitis $B$ vaccine in premature infants. Am J Trop Med Public Health. 1991;22:39-40.

43. Sadeck LS, Ramos JL. Resposta imune à vacinação contra a hepatite $B$ em recém-nascidos pré-termo no primeiro dia de vida. J Pediatr (Rio J). 2004;80:113-8.

44. Slack MH, Schapira D. Severe apneas following immunization in premature infants. Arch Dis Child Fetal Neonatal Ed. 1999;81: F67-8.

45. D'Angio CT, Maniscalco WN, Pichichero ME. Immunologic response of extremely premature infants to tetanus, $\mathrm{HiB}$ and polio immunizations. Pediatrics. 1995;96:18-22.

46. Munoz A, Salvador A, Brodsky NL, Arbeter AM, Porat R. Antibody response of low birth weight infants to $\mathrm{HiB}$ conjugate vaccine. Pediatrics. 1995;96:216-9.

47. Shinefield $H$, Black $S$, Ray $P$, Fireman B, Schwalbe J, Lewis E. Efficacy, immunogenicity and safety of heptavalent pneumococcal conjugate vaccine in low birth weight and preterm infants. Pediatr Infect Dis J. 2002;21:182-6.

48. Faldella G, Alessandroni R, Magini GM, Perrone A, Sabatini MR, Vancini $A$, et al. The preterm infant's antibody response to a combined diphtheria, tetanus, acellular pertussis and hepatitis B vaccine. Vaccine. 1998;16:1646-9.

49. Omeñaca F, Garcia-Sicilia J, Boceta R, Garcia-Corbeira P, Romero A, Lopez G, et al. Immunogenicity of a combined DTPaHBV-IPV $+\backslash$ Hib vaccine in preterm infants ( $<37$ weeks) as a primary vaccination course. World Congress of Pediatric Infectious Diseases: book of abstracts. Santiago: 2002. p. 46.

50. Saenger K, Dobbelaere L, Schuerman. Immunogenicity and safety of a combined DTPa-HBV-IPV+\Hib vaccine when coadministered with 7-valent pneumococcal conjugate vaccine. World Congress of Pediatric Infectious Diseases: book of abstracts. Santiago: 2002; p. 46.

51. Pfister RE, Aeschbach V, Niksic-Stuber V, Martin BC, Siegrist CA. Safety of DTaP-based combined immunization in very-lowbirth-weight premature infants: frequent but mostly benign cardiorespiratory events. J Pediatr. 2004;145:58-66.

\section{Correspondence:}

Eduardo Carlos Tavares

Rua Fernandes Tourinho, 840/1402

CEP 30112-000 - Belo Horizonte, MG

Brazil

Phone: +55 (31) 3281.3075 / 3282.5645

E-mail: etavares@medicina.ufmg.br or ectavares@terra.com.br 